\title{
Phenotypic analysis of antibiotic resistance and genotypic study of the vacA, cagA, iceA, oipA and babA genotypes of the Helicobacter pylori strains isolated from raw milk
}

\author{
Reza Ranjbar ${ }^{1 *}$, Farid Yadollahi Farsani ${ }^{2}$ and Farhad Safarpoor Dehkordi ${ }^{3}$
}

\begin{abstract}
Background: Foods with animal origins and particularly milk play a considerable role in transmission of Helicobacter pylori. The current study was performed to assess phenotypic characters of antibiotic resistance and genotyping pattern of vacA, cagA, iceA, oipA and babA2 alleles amongst the $\mathrm{H}$. pylori strains isolated from raw milk.

Methods: Six-hundred and thirty raw milk samples were collected and cultured on Wilkins Chalgren anaerobe media. Antibiotic resistance and genotyping patterns were studied using disk diffusion and PCR, respectively.

Results: Sixty-seven out of 630 (10.63\%) raw milk samples were positive for H. pylori. Ovine raw milk (17.27\%) samples had the highest prevalence of H. pylori, while camel (5.00\%) had the lowest. H. pylori strains harbored the highest prevalence of resistance against ampicillin (82.08\%), tetracycline (76.11\%), amoxicillin (74.62\%), metronidazole (65.67\%) and erythromycin (53.73\%). Prevalence of resistance against more than 10 types of antibiotics was $17.91 \%$. VacA sla (83.58\%), mla (80.59\%), s2 (77.61\%) and $m 2$ (68.65\%), cagA (73.13\%) and babA2 (44.77\%) were the most commonly detected genotypes. We found that S1am1a (56.71\%), s2m1a (56.71\%), s1 am2 (43.28\%) and s2 m2 (43.28\%) were the most commonly detected genotyping pattern. Frequency of cagA-, oipA- and babA2- genotypes were $26.86 \%, 62.68 \%$ and $55.22 \%$, respectively. We found that $\mathrm{S1a} / \mathrm{cag} A+/$ iceA1/oipA-/babA2(28.35\%), m1a/cagA+/iceA1/oipA-/babA2- (28.35\%) and s2/cagA+/iceA1/oipA-/babA2- (26.86\%) were the most commonly detected combined genotyping pattern.

Conclusions: Simultaneous presence of vacA, cagA, iceA, oipA and babA2 genotypes in antibiotic resistant $H$. pylori strains indicates important public health issue regarding the consumption of raw milk. However, additional researches are required to find molecular genetic homology and other epidemiological aspects of $H$. pylori in milk.
\end{abstract}

Keywords: Helicobacter pylori, Raw milk, Antibiotic resistance, Genotyping

\footnotetext{
* Correspondence: ranjbar@bmsu.ac.ir

${ }^{1}$ Molecular Biology Research Center, Systems Biology and Poisonings

Institute, Baqiyatallah University of Medical Sciences, Tehran, Iran

Full list of author information is available at the end of the article
}

(c) The Author(s). 2018 Open Access This article is distributed under the terms of the Creative Commons Attribution 4.0 International License (http://creativecommons.org/licenses/by/4.0/), which permits unrestricted use, distribution, and reproduction in any medium, provided you give appropriate credit to the original author(s) and the source, provide a link to the Creative Commons license, and indicate if changes were made. The Creative Commons Public Domain Dedication waiver (http://creativecommons.org/publicdomain/zero/1.0/) applies to the data made available in this article, unless otherwise stated. 


\section{Background}

Milk of animals provide a package of key nutrients that are difficult to obtain in diets with limited or no dairy products [1]. Dissimilarly, raw milk is not necessarily safe, as evidenced by higher rates of foodborne illnesses associated with its consumption [2-6]. Likewise, there were so many investigations about the considerable prevalence of some specific foodborne pathogens in raw milk [2-6].

Helicobacter pylori (H. pylori) is a microaerophilic and Gram-negative spiral coccoid flagellated bacterium with 2 to $4 \mu \mathrm{m}$ in length and 0.5 to $1 \mu \mathrm{m}$ in width. It is known as one of the main causative agents of duodenal ulcer, peptic ulcer disease, gastric adenocarcinoma, type $\mathrm{B}$ gastritis and gastric B-cell lymphoma [7-9]. Human stomach is considered as a main reservoir of $H$. pylori strains [7-9]. In keeping with this, foods with animal origins may play an imperative role in transmission of $H$. pylori infections to human [7-9]. Suitable conditions including $\mathrm{pH}$, activated water (AW), moisture and temperature cause $H$. pylori to easily survive in milk [10]. Raw milk [10], pasteurized milk [7-9] and even sterilized food samples [10] have been introduced as possible emerging sources of $H$. pylori infections. Vacuolating Cytotoxin A ( $v a c A)$ and Cytotoxin Associated Gene A ( $\operatorname{cag} A)$ are two important virulence genes with high importance in the pathogenicity of $H$. pylori infections [7-10]. The vacA gene is polymorphic, comprising variable signal regions (type $s 1$ or $s 2$ ) and mid-regions (type $m 1$ or $m 2$ ). The $s 1$ type is additionally divided into $s 1 a, s 1 b$ and $s 1 c$ and the $m 1$ into $m 1 a$ and $m 1 b$ subtypes. The cagA gene has been detected in the severe cases of gastrointestinal disorders and peptic ulcers [7-10]. Induced by contact with the epithelium antigen (ice $A$ ), outer inflammatory protein (oip) and blood group antigen-binding adhesin gene $(b a b A)$ are other important pathogenic genotypes of the $H$. pylori strains [7-11]. Genotyping using these virulence markers is considered as one of the best approaches to study the correlations between $H$. pylori isolates from different samples [11].

Antibiotic therapy is one of the best aspects of treatments for $H$. pylori infections. However, therapeutic options have become somewhat restricted because of the presence of severe resistance in some strains of this bacterium [12]. Documented data disclosed that $H$. pylori strains harbored the high prevalence of resistance against different types of antibiotics [12].

Data on the epidemiology and transmission of $H$. pylori is extremely significant in order to prevent its distribution and to identify high-risk populations, especially in areas that have high rates of infections such as Iran $[7-10,13,14]$. Considering the indistinct epidemiological aspects of $H$. pylori in milk and due to the high prevalence of $H$. pylori all-around the world [7-14], the present investigation was performed in order to study the prevalence rate, genotyping patterns and phenotypic evaluation of antibiotic resistance of the $H$. pylori strains isolated from raw milk samples of bovine, ovine, caprine, buffalo and camel.

\section{Methods \\ Samples}

From January to March 2018, total 630 raw milk samples of bovine $(n=120)$, ovine $(n=110)$, caprine $(n=130)$, buffalo $(n=130)$ and camel $(n=140)$ were arbitrarily collected from the supermarkets of diverse areas of Isfahan province, Iran. All milk samples were collected from traditional dairy farms. Milk samples were kept at refrigerator. Throughout milk collection, the first few squirts were overlooked. The animals which their milk samples collected for this research were clinically healthy, and the milk samples displayed natural physical (color, odor, $\mathrm{pH}$, and density) constancy. Samples $(50 \mathrm{ml}$, in sterile glass bottles) were transported in ice-cooled flasks (at $4{ }^{\circ} \mathrm{C}$ ) to the laboratory within two hours after collection.

\section{Isolation of helicobacter pylori}

Isolation of $H$. pylori bacteria was performed using the culture technique $[7-10,13,14]$. Twenty-five milliliters of milk sample were used for this purpose. Wilkins Chalgren anaerobe broth (Oxoid Ltd., Basingstoke, UK) was used for this purpose. Microaerophilic conditions (5\% oxygen, $85 \%$ nitrogen and $10 \% \mathrm{CO}_{2}$ ) was prepared using the MART system (MART system, Lichtenvoorde, The Netherland).

\section{DNA extraction and 16S rRNA-based PCR confirmation}

Distinctive colonies of $H$. pylori were additionally approved using the $16 S$ rRNA-based PCR method. Typical colonies were sub-cultured on Wilkins Chalgren anaerobe broth supplemented with same materials mentioned above [15]. Genomic DNA was then extracted from colonies using a DNA extraction kit (Thermo Fisher Scientific, St. Leon-Rot, Germany). Procedure was performed rendering to the manufacturer's guidelines. Purity (A260/A280) and concentration of extracted DNA were then checked (NanoDrop, Thermo Scientific, Waltham, MA, USA). The truth of the DNA was assessed on a $2 \%$ agarose gel stained with ethidium bromide $(0.5 \mu \mathrm{g} / \mathrm{mL})$ (Thermo Fisher Scientific, St. Leon-Rot, Germany). Polymerase Chain Reaction (PCR) was performed using a PCR thermal cycler (Eppendorf Co., Hamburg, Germany) according to reported procedure [15].

\section{Study the antibiotic resistance pattern}

There are no accepted standardized methods for testing $H$. pylori antimicrobial susceptibilities and the protocols 
used in this study were based on recently published guidelines [16] and also those of Performance Standards for Antimicrobial Susceptibility Testing- Clinical and Laboratory Standards Institute - NCCLS, 2007 [17]. Briefly, bacterial suspensions were adjusted to the 0.5 McFarland standard (equivalent to $1-2 \times 10^{8} \mathrm{cfu} / \mathrm{ml}$ ) and were used to inoculate Muller Hinton agar plates (Merck, Germany). Antimicrobial disks (ampicillin $(10 \mu \mathrm{g})$, levofloxacin $(5 \mu \mathrm{g})$, metronidazole $(5 \mu \mathrm{g})$, clarithromycin $(2 \mu \mathrm{g})$, amoxicillin $(10 \mu \mathrm{g})$, streptomycin $(10 \mu \mathrm{g})$, cefsulodin $(30 \mu \mathrm{g})$, erythromycin $(5 \mu \mathrm{g})$, tetracycline $(30 \mu \mathrm{g})$, trimethoprim $(25 \mu \mathrm{g})$, furazolidone $(1 \mu \mathrm{g})$, rifampin $(30 \mu \mathrm{g})$, and spiramycin $(100 \mu \mathrm{g})$ (Oxoid, UK)) were applied and the plates were incubated under microaerophilic conditions at $35{ }^{\circ} \mathrm{C}$ for $16-18 \mathrm{~h}$. The zones of growth inhibition produced by each antibiotic were measured and interpreted by standard procedure. Reference strains NCTC 13206 (CCUG 38770) and NCTC 13207 (CCUG 38772) were included as quality controls [18].

\section{Genotyping analysis}

Frequency of $v a c A, \operatorname{cag} A$, ice $A, \operatorname{oip} A$ and $b a b A$ alleles were assessed using PCR [19-22]. Table 1 characterizes the set of primers and PCR circumstances applied for genotyping of vacA, cagA, iceA, oipA and babA alleles. Initially, all samples were subjected to pre-tests to found suitable time, temperature and volume of reaction. A programmable DNA thermo-cycler (Eppendorf Mastercycler 5330, Eppendorf-Nethel-Hinz GmbH, Hamburg, Germany) was used in all PCR reactions. PCR grade water and $H$. pylori standard strains (SS1, 26,695, Tx30, J99, 88-23 and 84-183) were used as negative and positive controls, respectively. Ten microliters of PCR product were exposed to electrophoresis in a $2 \%$ agarose gel in $1 \mathrm{X}$ TBE buffer at $80 \mathrm{~V}$ for $30 \mathrm{~min}$, stained with SYBR Green. The UVI doc gel documentation systems (Grade GB004, Jencons PLC, London, UK) was applied for analysis of images.

\section{Statistical analysis}

Data were subjected to Microsoft office Excel (version 15; Microsoft Corp., Redmond, WA, USA). Statistical analysis was performed by means of the SPSS 21.0 statistical software (SPSS Inc., Chicago, IL, USA). Chi-square test and Fisher's exact two-tailed test were applied to measure any significant relationship. $P$ value $<0.05$ was considered as statistical significant level.

\section{Results}

Table 2 represents the prevalence of $H$. pylori in different types of raw milk samples. Sixty-seven out of 630 (10.63\%) raw milk samples were positive for $H$. pylori strains. All isolates were also approved by the $16 \operatorname{Sr} R N A$ gene PCR amplification. Ovine (17.27\%) and caprine (13.84\%) raw milk samples had the highest prevalence of H. pylori strains, while camel $(5.00 \%)$ had the lowest. Statistically significant difference was seen between type of samples and prevalence of $H$. pylori strains $(P<0.05)$.

Table 3 represents the antibiotic resistance pattern of H. pylori strains isolated from different types of raw milk samples. H. pylori strains harbored the highest prevalence of resistance against ampicillin $(82.08 \%)$, tetracycline (76.11\%), amoxicillin (74.62\%), metronidazole (65.67\%) and erythromycin (53.73\%) antibiotic agents. Furthermore, H. pylori strains harbored the lowest prevalence of resistance against cefsulodin (13.43\%), furazolidone $(13.43 \%)$, spiramycin $(16.41 \%)$ and streptomycin (23.88\%). Moreover, prevalence of resistance against clarithromycin, levofloxacin, rifampin and trimethoprim antibiotic agents were $47.76 \%, 38.80 \%$, $32.83 \%$ and $34.32 \%$, respectively. Statistically significant difference was seen between type of samples and prevalence of antibiotic resistance $(P<0.05)$. Figure 1 represents the distribution of multi-drug resistant $H$. pylori strains isolated from different types of raw milk samples. We found that all of the $H$. pylori strains isolated from raw milk samples at least had resistance against 3 different types of antibiotics, while prevalence of resistance against more than 3 types of antibiotics (etc) was $94.02 \%$.

Table 4 represents the distribution of genotypes amongst the $H$. pylori strains isolated from different types of raw milk samples. VacA s1a (83.58\%), m1a (80.59\%), s2 (77.61\%) and $m 2$ (68.65\%), cagA (73.13\%) and babA2 (44.77\%) were the most commonly detected genotypes amongst the $H$. pylori strains isolated from different types of raw milk samples. VacA s1c (10.44\%), $m 1 b(28.35 \%)$ and $s 1 b(32.83 \%)$, iceA2 (19.40\%) and oipA (37.31\%) had the lowest prevalence amongst the $\mathrm{H}$. pylori strains isolated from different types of raw milk samples. Statistically significant difference was seen between type of samples and prevalence of genotypes $(P<0.05)$. Additionally, statistically significant difference was seen between the prevalence of iceA1 and iceA2 genotypes $(P<0.05)$.

Table 5 represents the genotyping pattern of $H$. pylori strains isolated from different types of raw milk samples. S1am1a (56.71\%), s2m1a (56.71\%), s1 am2 (43.28\%) and s2 $m 2$ (43.28\%) were the most commonly detected genotyping pattern of the $v a c A$ alleles of $H$. pylori strains isolated from different types of raw milk samples. Distribution of cagA-, oipA- and babA2- genotypes were $26.86 \%, 62.68 \%$ and $55.22 \%$, respectively. We found that $10.44 \%$ of $H$. pylori strains harbored iceA1/iceA2 genotyping pattern. $S 1 \mathrm{~cm} 1 b(1.49 \%), s 1 \mathrm{~cm} 2(4.47 \%), s 1 b m 1 b$ (7.46\%), s1cm1a (7.46\%), s1bm2 (11.94\%), s2m1b (16.41\%) and s1bm1a (16.41\%) had the lowest prevalence 
Table 1 Set of primers and PCR circumstances applied for genotyping of vacA, cagA, iceA, oipA and babA alleles

\begin{tabular}{|c|c|c|c|c|c|}
\hline \multicolumn{2}{|l|}{ Genes } & Primer Sequence (5'-3') & Size of product (bp) & Volume of PCR reaction $(50 \mu l)$ & PCR programs \\
\hline \multicolumn{2}{|c|}{$\operatorname{VacA} s_{1} a$} & $\begin{array}{l}\text { F: CTCTCGCTITAGTAGGAGC } \\
\text { R: CTGCTTGAATGCGCCAAAC }\end{array}$ & 213 & \multirow{7}{*}{$\begin{array}{l}5 \mu \mathrm{L} \text { PCR buffer } 10 \times 1.5 \mathrm{mM} \mathrm{Mgcl} \\
200 \mu \mathrm{M} \text { dNTP (Thermo Fisher } \\
\text { Scientific, St. Leon-Rot, Germany) } \\
0.5 \mu \mathrm{M} \text { of each primers F \& R } \\
1.25 \cup \text { Taq DNA polymerase } \\
\text { (Thermo Fisher Scientific, } \\
\text { St. Leon-Rot, Germany) } \\
\text { 2.5 } \mu \text { L DNA template }\end{array}$} & \multirow{7}{*}{ 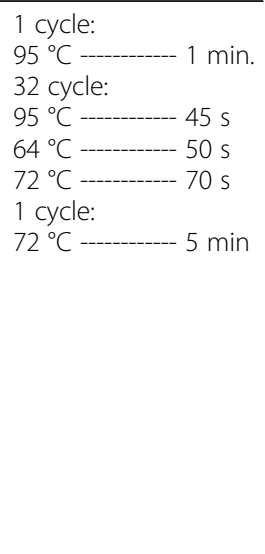 } \\
\hline \multicolumn{2}{|c|}{$\operatorname{Vac} A s, b$} & $\begin{array}{l}\text { F: AGCGCCATACCGCAAGAG } \\
\text { CTGCTTGAATGCGCCAAAC }\end{array}$ & 187 & & \\
\hline \multicolumn{2}{|c|}{$\operatorname{VacA} s_{1} \mathrm{C}$} & $\begin{array}{l}\text { F: CTCTCGCTTAAGTGGGGYT } \\
\text { R: CTGCTTGAATGCGCCAAAC }\end{array}$ & 213 & & \\
\hline \multicolumn{2}{|c|}{$\operatorname{VacA~s} s_{2}$} & $\begin{array}{l}\text { F: GCTAACACGCCAAATGATCC } \\
\text { R: CTGCTTGAATGCGCCAAAC }\end{array}$ & 199 & & \\
\hline \multicolumn{2}{|c|}{$\operatorname{VacA} m_{1} a$} & $\begin{array}{l}\text { F: GGTCAAAATGCGGTCATGG } \\
\text { R: CCATTGGTACCTGTAGAAAC }\end{array}$ & 290 & & \\
\hline \multicolumn{2}{|c|}{$\operatorname{VacA} m_{1} b$} & $\begin{array}{l}\text { F: GGCCCCAATGCAGTCATGGA } \\
\text { R: GCTGTTAGTGCCTAAAGAAGCAT }\end{array}$ & 291 & & \\
\hline \multicolumn{2}{|c|}{$\operatorname{VacA} m_{2}$} & $\begin{array}{l}\text { F: GGAGCCCCAGGAAACATTG } \\
\text { R: CATAACTAGCGCCTTGCA }\end{array}$ & 352 & & \\
\hline \multicolumn{2}{|l|}{$\operatorname{Cag} A$} & $\begin{array}{l}\text { F: GATAACAGCCAAGCTITGAGG } \\
\text { R: CTGCAAAAGATTGTTTGGCAGA }\end{array}$ & 300 & $\begin{array}{l}5 \mu \mathrm{L} \text { PCR buffer } 10 \mathrm{X} \\
2 \mathrm{mM} \mathrm{Mgcl} 2 \\
150 \mu \mathrm{M} \text { dNTP (Thermo Fisher } \\
\text { Scientific, St. Leon-Rot, Germany) } \\
0.75 \mu \mathrm{M} \text { of each primers F \& R } \\
1.5 \mathrm{U} \text { Taq DNA polymerase } \\
\text { (Thermo Fisher Scientific, } \\
\text { St. Leon-Rot, Germany) } \\
3 \mu \mathrm{L} \text { DNA template }\end{array}$ & 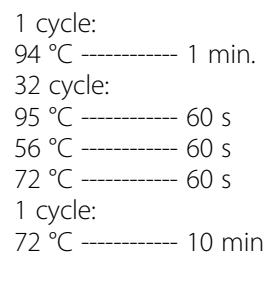 \\
\hline \multirow[t]{2}{*}{ IceA } & ICeAl & $\begin{array}{l}\text { F: GTGTIITIAACCAAAGTATC } \\
\text { R: CTATAGCCASTYTCTTTGCA }\end{array}$ & 247 & \multirow{2}{*}{$\begin{array}{l}5 \mu \mathrm{L} \text { PCR buffer } 10 \times 2 \mathrm{mM} \mathrm{Mgcl} 2 \\
150 \mu \mathrm{M} \text { dNTP (Thermo Fisher } \\
\text { Scientific, St. Leon-Rot, Germany) } \\
0.75 \mu \mathrm{M} \text { of each primers F \& R } \\
1.5 \cup \text { Taq DNA polymerase } \\
\text { (Thermo Fisher Scientific, } \\
\text { St. Leon-Rot, Germany) } \\
3 \mu \mathrm{L} \text { DNA template }\end{array}$} & \multirow{2}{*}{ 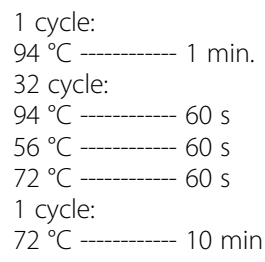 } \\
\hline & ICeA2 & $\begin{array}{l}\text { F: GTTGGGTATATCACAATTTAT } \\
\text { R: TTRCCCTATTTCTAGTAGGT }\end{array}$ & $229 / 334$ & & \\
\hline \multicolumn{2}{|l|}{ OipA } & $\begin{array}{l}\text { F: GTIITGATGCATGGGATTT } \\
\text { R: GTGCATCTCTTATGGCTIT }\end{array}$ & 401 & $\begin{array}{l}5 \mu \mathrm{L} \text { PCR buffer } 10 \times 2 \mathrm{mM} \mathrm{Mgcl} \\
150 \mu \mathrm{M} \text { dNTP (Thermo Fisher } \\
\text { Scientific, St. Leon-Rot, Germany) } \\
0.75 \mu \mathrm{M} \text { of each primers F \& R } \\
1.5 \cup \text { Taq DNA polymerase } \\
\text { (Thermo Fisher Scientific, } \\
\text { St. Leon-Rot, Germany) } \\
3 \mu \mathrm{L} \text { DNA template }\end{array}$ & 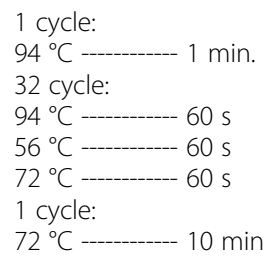 \\
\hline \multicolumn{2}{|l|}{$B a b A$} & $\begin{array}{l}\text { F: CCAAACGAAACAAAAAGCGT } \\
\text { R: GCTTGTGTAAAAGCCGTCGT }\end{array}$ & $105-124$ & $\begin{array}{l}5 \mu \mathrm{L} \text { PCR buffer } 10 \times 2 \mathrm{mM} \mathrm{Mgcl} \\
150 \mu \mathrm{M} \text { dNTP (Thermo Fisher } \\
\text { Scientific, St. Leon-Rot, Germany) } \\
0.75 \mu \mathrm{M} \text { of each primers F \& R } \\
1.5 \cup \text { Taq DNA polymerase } \\
\text { (Thermo Fisher Scientific, } \\
\text { St. Leon-Rot, Germany) } \\
3 \mu \mathrm{L} \text { DNA template }\end{array}$ & 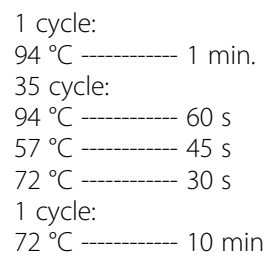 \\
\hline
\end{tabular}

amongst different genotyping patterns of $H$. pylori strains.

Table 6 represents the combined genotyping pattern of H. pylori strains isolated from different types of raw milk samples. We found that s1a/cagA+/iceA1/oipA-/babA2(28.35\%), m1a/cagA+/iceA1/oipA-/babA2- (28.35\%), s2/ cagA+/iceA1/oipA-/babA2- (26.86\%), s1a/cagA+/iceA1/ oipA-/babA2+ (25.37\%), m1a/cagA+/iceA1/oipA-/babA2+ (25.37\%), s2/cagA+/iceA1/oipA-/babA2+ (23.88\%), s1a/ cagA+/iceA1/oipA+/babA2- (22.38\%) and m2/cagA +/iceA1/oipA-/babA2+ (22.38\%) were the most commonly detected combined genotyping pattern of $H$. pylori strains isolated from different types of raw milk samples. There were no detected $H$. pylori strains positive for s1b/cagA -/iceA2/oipA+/babA2+, s1c/cagA+/iceA1/oipA+/babA2+, s1c/cagA+/iceA1/oipA+/babA2-, s1c/cagA+/iceA2/oipA +/babA2+, s1c/cagA+/iceA2/oipA+/babA2-, s1c/cagA +/iceA2/oipA-/babA2+, s1c/cagA-/iceA1/oipA+/babA2+, s1c/cagA-/iceA1/oipA+/babA2-, $\quad$ s1c/cagA-/iceA1/oipA -/babA2+, s1c/cagA-/iceA2/oipA+/babA2+, s1c/cagA -/iceA2/oipA+/babA2-, s1c/cagA-/iceA2/oipA-/babA2+, s1c/cagA-/iceA2/oipA-/babA2-, m1b/cagA-/iceA1/oipA 
Table 2 Prevalence of $H$. pylori in different types of raw milk

\begin{tabular}{llll}
$\begin{array}{lll}\text { samples } \\
\text { Ram milk }\end{array}$ & $\begin{array}{l}\text { No samples } \\
\text { collected }\end{array}$ & $\begin{array}{l}\text { N (\%) of H. pylori } \\
\text { positive samples }\end{array}$ & $\begin{array}{l}\text { H. pylori 16SrRNA PCR } \\
\text { confirmation (\%) }\end{array}$ \\
\hline Bovine & 120 & $9(7.50)$ & $9(7.50)$ \\
Ovine & 110 & $19(17.27)$ & $19(17.27)$ \\
Caprine & 130 & $18(13.84)$ & $18(13.84)$ \\
Buffalo & 130 & $14(10.76)$ & $14(10.76)$ \\
Camel & 140 & $7(5.00)$ & $7(5.00)$ \\
Total & 630 & $67(10.63)$ & $67(10.63)$ \\
\hline
\end{tabular}

+/babA2+ and s1b/cagA-/iceA2/oipA+/babA2+ combined genotyping patterns. Prevalence of $\mathrm{s} 1 \mathrm{~b} / \mathrm{cagA}-/ \mathrm{ice} \mathrm{A} 1 / \mathrm{oipA}$ +/babA2+, s1b/cagA-/iceA1/oipA+/babA2-, s1b/cagA -/iceA2/oipA+/babA2-, s1c/cagA+/iceA1/oipA-/babA2+, s1c/cagA+/iceA2/oipA-/babA2-, s1c/cagA-/iceA1/oipA -/babA2-, s2/cagA-/iceA2/oipA+/babA2+, m1b/cagA -/iceA1/oipA+/babA2-, m1b/cagA-/iceA1/oipA-/babA2+, $\mathrm{m} 1 \mathrm{~b} / \mathrm{cagA}-$ /iceA2/oipA+/babA2- and $\mathrm{m} 2 /$ cagA-/iceA2/ oipA+/babA2+ (1.49\%) were lower than other detected combined genotyping patterns.

\section{Discussion}

H. pylori is a common bacterium with high microbiological and clinical importance and about $50 \%$ of the world's population, depending to the geographic location considered, has been estimated to have been infected with this organism. Despite the high incidence of the infection, the reservoir for $H$. pylori and the routes of infection are still indeterminate and various routes of transmission have been recommended [23]. Moreover, epidemiological investigations suggest that transmission of $H$. pylori between individuals happens both via the oral-oral and fecal-oral routes [23]. In keeping with this, fecal-oral transmission has more significant implications than since $H$. pylori may occur in food and water supplies subsequent to fecal contamination [24]. Besides, the isolation of $H$. pylori in drinking water [13, 14], raw vegetables $[7,9]$, salads $[7,9]$, meat $[25,26]$, ready to eat foods [27, 28], sterilized foods [29, 30] and foods with animal origin such as milk [31-35], suggests that these foods may act as vehicles for transmission of $H$. pylori to human population.

The present study was performed to assess the prevalence rate, genotyping patterns and antibiotic resistance properties of $H$. pylori strains isolated from different types of raw milk samples. Totally, $10.63 \%$ of raw milk samples were positive for $H$. pylori strains. Prevalence of $H$. pylori strains in raw milk samples of bovine, ovine, caprine, buffalo and camel were 7.50, 17.27, 13.84, 10.76 and $5.00 \%$, respectively. Several studies have been conducted in this field. Talaei et al. (2015) [36] reported that the total prevalence of $H$. pylori strains amongst the cow, sheep, goat and buffalo milk samples were 16.00, $13.79,4.76,13.33$ and 20.00\%, respectively. Quaglia et al. (2008) [35] determined that the prevalence of $H$. pylori strains in sheep, cow and goat milk samples were $33.00 \%, 50.00 \%$ and $25.60 \%$, respectively. Mousavi et al. (2014) [10] described that the prevalence of $H$. pylori strains in bovine, ovine, caprine, buffalo and camel milk samples were 16.66, 35.00, 28.00, 15.00 and 13.30\%, respectively. Rahimi and Kheirabadi (2012) [37] noted that the prevalence of $H$. pylori strains in raw bovine, ovine, caprine, buffalo and camel milk samples were $1.41,12.20,8.70,23.40$ and $3.60 \%$, respectively. Osman et al. (2015) [38] revealed that the prevalence of $H$. pylori in raw milk samples of different parts of Sudan had a range of 7 to $38 \%$. Similar results have been reported for the high prevalence of $H$. pylori in milk samples from Japan (72.20\%) [32], Greece (20.00\%) [34], Italy 1.80\%) [39] and Iran (16.00\%) [40].

Foods presenting intrinsic factors, including water activity higher than 0.97 and $\mathrm{pH}$ ranging from 4.9 to 6.0 such as raw milk, theoretically could provide conditions for survival of $H$. pylori [7-9]. Therefore, it is not surprising that the $H$. pylori strains has the high prevalence in raw milk samples of our investigation. High prevalence rate of $H$. pylori in milk samples of our research is may be due to the low levels of hygienic conditions of milking procedure. Furthermore, considering the boost prevalence of $H$. pylori in healthy human carrier, contamination due to poor hygiene management of open package of milk, has more important implications for the transmission of the infection through foods. Milk, that could become contaminated during production or because of low hygiene after the open of package, is considered to be one of the most likely vehicles for infection $[31,32]$. Insufficient post-processing hygienic management of the milk, can carry the contamination of the matrix by humans. Despite of the low prevalence of $H$. pylori strains in some kinds of studied milk samples, the infectious dose of $H$. pylori is presumably low [31, 32]. Therefore, it is an important public health threat regarding the consumption of raw milk. The urea-dependent acid resistance of $H$. pylori may account for the long-term survival of $H$. pylori in an acidic environment including raw milk [29]. Higher prevalence of $H$. pylori in raw ovine milk samples is may be due to the more suitable conditions present in ovine milk such as higher fat, protein and water activity and also optimum $\mathrm{pH}$. Furthermore, ovine milk may have a higher qualification for growth and survival of $H$. pylori strains. Moreover, differences in the feed of ovine with bovine, buffalo, camel and even caprine species may affect the prevalence rate of bacteria presented in their milk. Higher prevalence of $H$. pylori in raw ovine milk was also reported by previous investigations [10, 31, 32, 34-43]. 


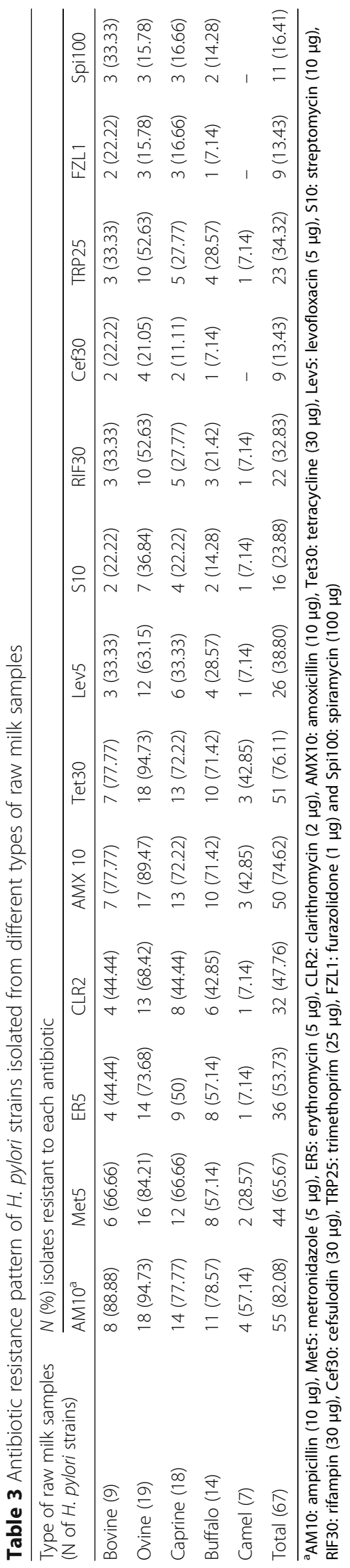




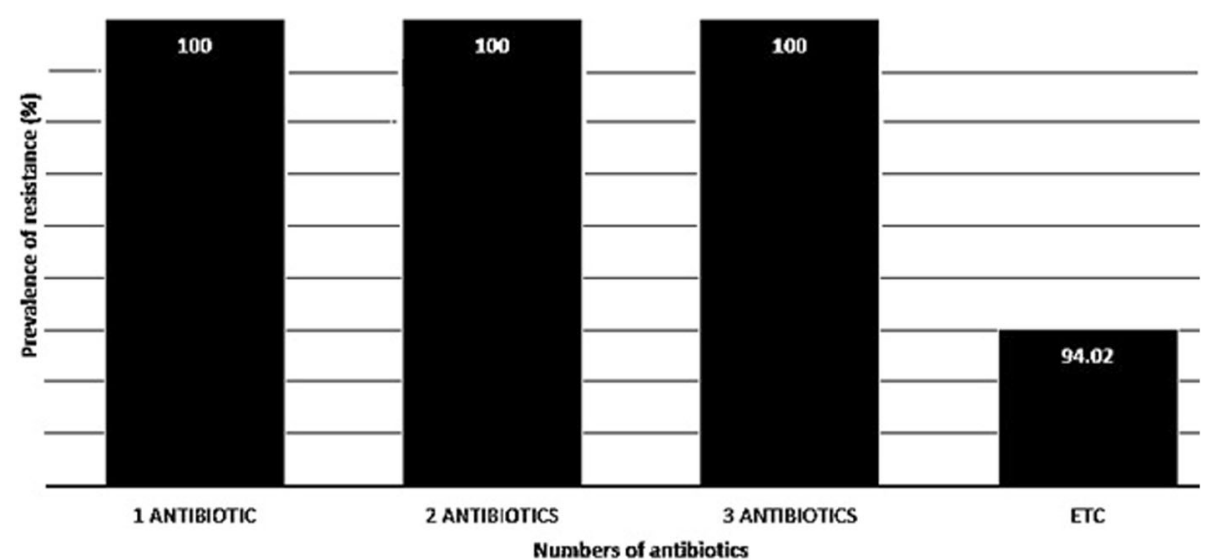

Fig. 1 Distribution of multidrug resistant $H$. pylori strains isolated from different types of raw milk. Multidrug resistant $H$. pylori strains were determined as those who had at least simultaneous resistance against 3 or more than 3 types of antibiotics

Using thorns and thistles in deserts and living away from humans and the polluted environment of cities are the most important probable reasons for the lower prevalence of $H$. pylori in camel milk. Lower prevalence of $H$. pylori in raw camel milk was also reported by previous investigations [10, 37, 44, 45].

We described that $H$. pylori bacteria exhibited the maximum prevalence of resistance against ampicillin, tetracycline, amoxicillin, metronidazole and erythromycin antibiotics. Boost prevalence of resistance against human-based antibiotics such as metronidazole, erythromycin, clarithromycin, levofloxacin, amoxicillin, streptomycin, rifampin, cefsulodin, trimethoprim, furazolidone and spiramycin in $H$. pylori bacteria isolated from raw milk samples characterized their anthropogenic origin. Reversely, boost prevalence of resistance against animal-based antibiotics such as ampicillin and tetracycline in $H$. pylori bacteria isolated from raw milk samples characterized their animal origin. As it displayed, majority of $H$. pylori bacteria exhibited resistance against human-based antibiotics. Extreme, illegal and prohibited prescription of antibiotics in medicine and also veterinary caused momentous surge in antibiotic resistance. Frequent researches have been accomplished, globally. Among plentiful examines performed on the antibiotic resistance of $H$. pylori bacteria, discoveries of Hemmatinezhad et al. (2016) [46] (amoxicillin (94.59\%), ampicillin (93.24\%), metronidazole (89.18\%), tetracycline (72.97\%) and erythromycin (58.10\%)), Yahaghi et al. (2014) [9] (metronidazole (77.96\%), amoxicillin (67.79\%), ampicillin (61.01\%), and erythromycin (23.72\%)) and Mousavi et al. (2014) [10] (ampicillin (84.4\%), tetracycline (76.6\%), erythromycin (70.5\%), metronidazole (70\%), and clarithromycin $(17.70 \%)$ ) were similar to our findings. Clinical investigations conducted in Iran, China, India, Nigeria, Taiwan, Senegal, Thailand, Saudi Arabia, Brazil, Egypt, Argentina and Colombia disclosed that H. pylori bacteria of human clinical specimens displayed boost prevalence of resistance against aminoglycosides, tetracyclines, penicillins, macrolides and metronidazole [47] which was parallel to our results.

We also found that vacA s1a, s2, m1a and $m 2$, cagA, iceA1, oipA and babA2 genotypes, slam1a, s2m1a, s1 am2, s2 m2, cagA-, oipA- and babA2- patterns and s1a/cagA+/iceA1/oipA-/babA2-, m1a/cagA+/iceA1/ oipA-/babA2-, s2/cagA+/iceA1/oipA-/babA2-, s1a/ cagA+/iceA1/oipA-/babA2+, m1a/cagA+/iceA1/oipA -/babA2+, s2/cagA+/iceA1/oipA-/babA2+, s1a/cagA +/iceA1/oipA+/babA2- and $\mathrm{m} 2 / \mathrm{cagA}+$ /iceA1/oipA $-/$ babA2+ combined genotyping patterns were the most commonly detected virulence characters of $H$. pylori strains isolated from raw milk samples. High prevalence of vacA, cagA, iceA1, oipA and babA2 genotypes was also reported in the $H$. pylori strains isolated from clinical samples of human and animal species [48-51]. Furthermore, high prevalence of these genotypes has been reported in the $H$. pylori strains isolated from different types of food samples [8-10, 14, 36, 42-45, 52]. Adjacent association of vacA, cagA, iceA, oipA and babA2 genotypes of $H$. pylori bacteria with secretion of interleukin-8 and cytotoxin, adhesion to gastric epithelial cells, occurrence of inflammatory effect, vacuolization, apoptosis procedure in gastric epithelial cells, peptic ulceration, increase acute neutrophilic infiltration, interleukin-10 secretion and inflammation, has been presented previously [48-50]. Since $H$. pylori isolates in our investigation harbored $v a c A, \operatorname{cag} A$, ice $A$, oipA and babA2 genotypes, therefore consumption of raw milk contaminated with virulent strains of $H$. pylori may aggravate duodenal ulceration, gastric mucosal atrophy and gastric cancer. Additionally, some of $H$. pylori isolates were simultaneously positive for more than one detected genotypes which poses their higher pathogenicity. Similar genotyping patterns of $H$. pylori strains 


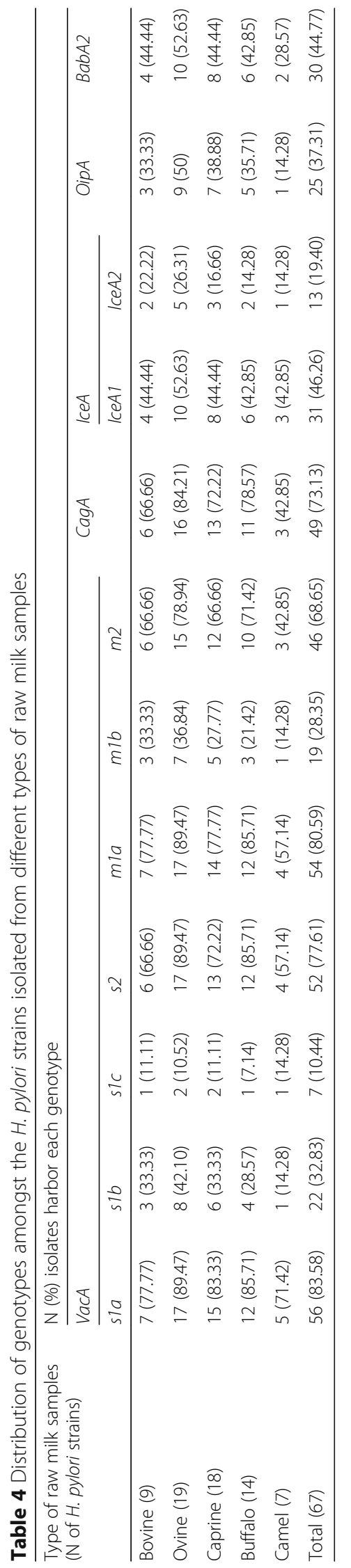




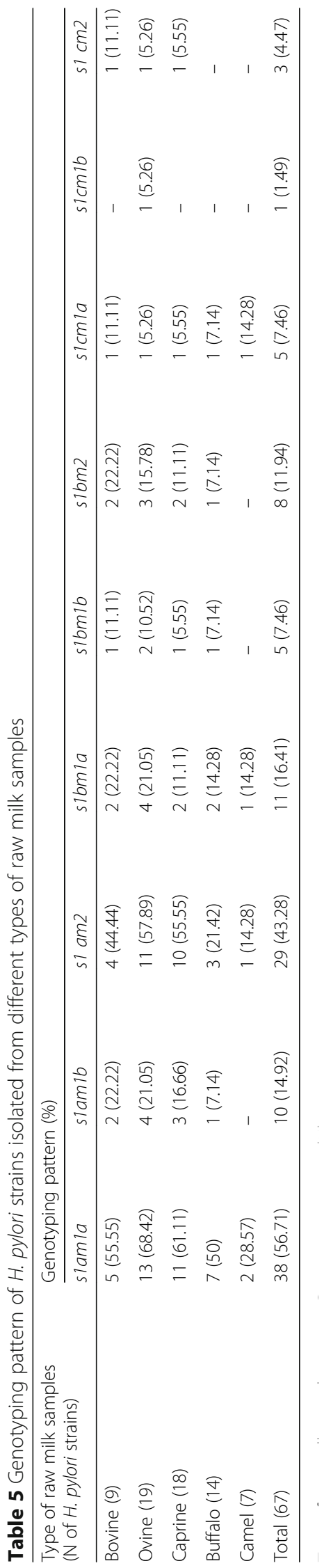




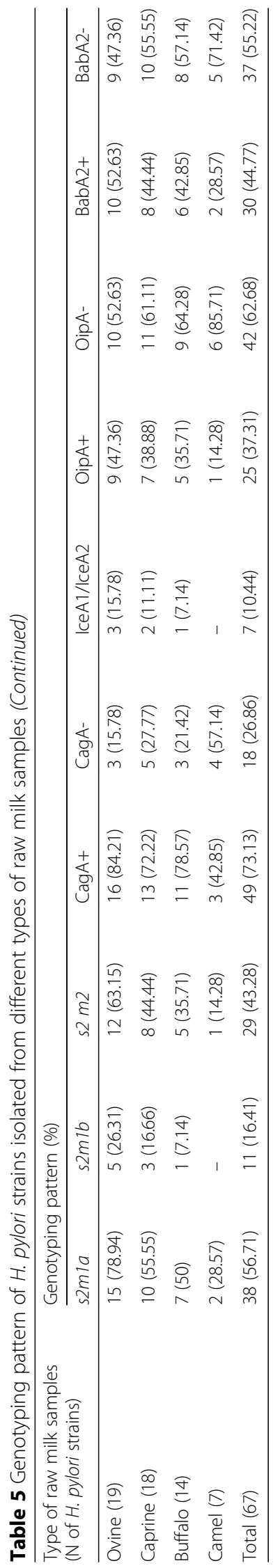


Table 6 Combined genotyping pattern of H. pylori strains isolated from different types of raw milk samples

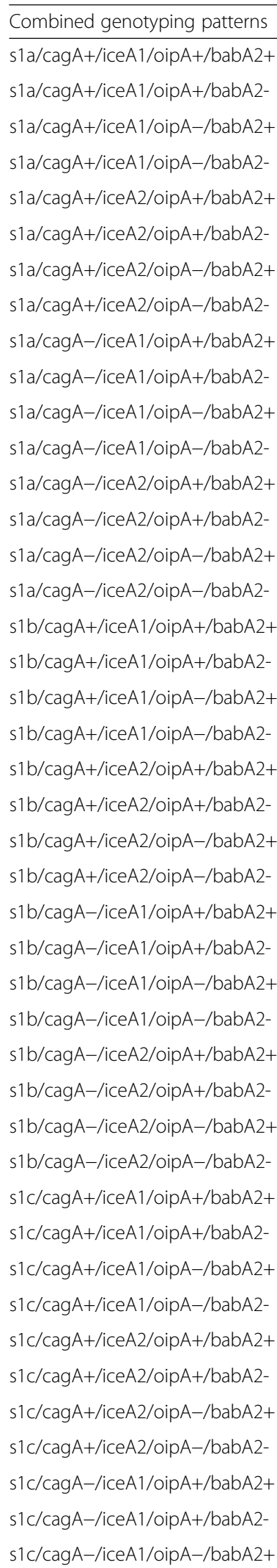

Table 6 Combined genotyping pattern of H. pylori strains isolated from different types of raw milk samples (Continued)

\begin{tabular}{|c|c|c|}
\hline Distribution ${ }^{\mathrm{a}}(\%)$ & Combined genotyping patterns & Distribution $^{\mathrm{a}}(\%)$ \\
\hline $13(19.40)$ & s1c/cagA-/iceA1/oipA-/babA2- & $1(1.49)$ \\
\hline $15(22.38)$ & s1c/cagA-/iceA2/oipA+/babA2+ & - \\
\hline $17(25.37)$ & s1c/cagA-/iceA2/oipA+/babA2- & - \\
\hline $19(28.35)$ & s1c/cagA-/iceA2/oipA-/babA2+ & - \\
\hline $4(5.97)$ & s1c/cagA-/iceA2/oipA-/babA2- & - \\
\hline $5(7.46)$ & s2/cagA+/iceA1/oipA+/babA2+ & $12(17.91)$ \\
\hline $6(8.95)$ & s2/cagA+/iceA1/oipA+/babA2- & $13(19.40)$ \\
\hline $7(10.44)$ & s2/cagA+/iceA1/oipA-/babA2+ & $16(23.88)$ \\
\hline $6(8.95)$ & s2/cagA+/iceA1/oipA-/babA2- & $18(26.86)$ \\
\hline $8(11.94)$ & s2/cagA+/iceA2/oipA+/babA2+ & $3(4.47)$ \\
\hline $8(11.94)$ & s2/cagA+/iceA2/oipA+/babA2- & $4(5.97)$ \\
\hline $10(14.92)$ & s2/cagA+/iceA2/oipA-/babA2+ & $6(8.95)$ \\
\hline $2(2.98)$ & s2/cagA+/iceA2/oipA-/babA2- & $6(8.95)$ \\
\hline $4(5.97)$ & s2/cagA-/iceA1/oipA+/babA2+ & $5(7.46)$ \\
\hline $5(7.46)$ & s2/cagA-/iceA1/oipA+/babA2- & $7(10.44)$ \\
\hline $5(7.46)$ & s2/cagA-/iceA1/oipA-/babA2+ & $9(13.43)$ \\
\hline $9(13.43)$ & s2/cagA-/iceA1/oipA-/babA2- & $10(14.92)$ \\
\hline $11(16.41)$ & s2/cagA-/iceA2/oipA+/babA2+ & $1(1.49)$ \\
\hline $12(17.91)$ & s2/cagA-/iceA2/oipA+/babA2- & $3(4.47)$ \\
\hline $14(20.89)$ & s2/cagA-/iceA2/oipA-/babA2+ & $4(5.97)$ \\
\hline $2(2.98)$ & s2/cagA-/iceA2/oipA-/babA2- & $5(7.46)$ \\
\hline $3(4.47)$ & m1a/cagA+/iceA1/oipA+/babA2+ & $12(17.91)$ \\
\hline $4(5.97)$ & m1a/cagA+/iceA1/oipA+/babA2- & $14(20.89)$ \\
\hline $5(7.46)$ & m1a/cagA+/iceA1/oipA-/babA2+ & $17(25.37)$ \\
\hline $1(1.49)$ & m1a/cagA+/iceA1/oipA-/babA2- & $19(28.35)$ \\
\hline $1(1.49)$ & m1a/cagA+/iceA2/oipA+/babA2+ & $4(5.97)$ \\
\hline $2(2.98)$ & m1a/cagA+/iceA2/oipA+/babA2- & $5(7.46)$ \\
\hline $2(2.98)$ & m1a/cagA+/iceA2/oipA-/babA2+ & $6(8.95)$ \\
\hline- & m1a/cagA+/iceA2/oipA-/babA2- & $6(8.95)$ \\
\hline $1(1.49)$ & m1a/cagA-/iceA1/oipA+/babA2+ & $6(8.95)$ \\
\hline $2(2.98)$ & m1a/cagA-/iceA1/oipA+/babA2- & $7(10.44)$ \\
\hline $2(2.98)$ & m1a/cagA-/iceA1/oipA-/babA2+ & $8(11.94)$ \\
\hline- & m1a/cagA-/iceA1/oipA-/babA2- & $10(14.92)$ \\
\hline- & m1a/cagA-/iceA2/oipA+/babA2+ & $2(2.98)$ \\
\hline $1(1.49)$ & m1a/cagA-/iceA2/oipA+/babA2- & $3(4.47)$ \\
\hline $2(2.98)$ & m1a/cagA-/iceA2/oipA-/babA2+ & $5(7.46)$ \\
\hline- & m1a/cagA-/iceA2/oipA-/babA2- & $5(7.46)$ \\
\hline- & m1b/cagA+/iceA1/oipA+/babA2+ & $8(11.94)$ \\
\hline- & m1b/cagA+/iceA1/oipA+/babA2- & $10(14.92)$ \\
\hline $1(1.49)$ & m1b/cagA+/iceA1/oipA-/babA2+ & $10(14.92)$ \\
\hline- & m1b/cagA+/iceA1/oipA-/babA2- & $13(19.40)$ \\
\hline- & m1b/cagA+/iceA2/oipA+/babA2+ & $2(2.98)$ \\
\hline- & m1b/cagA+/iceA2/oipA+/babA2- & $3(4.47)$ \\
\hline
\end{tabular}


Table 6 Combined genotyping pattern of H. pylori strains isolated from different types of raw milk samples (Continued)

\begin{tabular}{|c|c|}
\hline Combined genotyping patterns & Distribution $^{\mathrm{a}}(\%)$ \\
\hline m1b/cagA+/iceA2/oipA-/babA2+ & $4(5.97)$ \\
\hline m1b/cagA+/iceA2/oipA-/babA2- & $4(5.97)$ \\
\hline m1b/cagA-/iceA1/oipA+/babA2+ & - \\
\hline m1b/cagA-/iceA1/oipA+/babA2- & $1(1.49)$ \\
\hline m1b/cagA-/iceA1/oipA-/babA2+ & $1(1.49)$ \\
\hline m1b/cagA-/iceA1/oipA-/babA2- & $2(2.98)$ \\
\hline s1b/cagA-/iceA2/oipA+/babA2+ & - \\
\hline m1b/cagA-/iceA2/oipA+/babA2- & $1(1.49)$ \\
\hline m1b/cagA-/iceA2/oipA-/babA2+ & $2(2.98)$ \\
\hline m1b/cagA-/iceA2/oipA-/babA2- & $2(2.98)$ \\
\hline m2/cagA+/iceA1/oipA+/babA2+ & $11(16.41)$ \\
\hline m2/cagA+/iceA1/oipA+/babA2- & $13(19.40)$ \\
\hline m2/cagA+/iceA1/oipA-/babA2+ & $15(22.38)$ \\
\hline m2/cagA+/iceA1/oipA-/babA2- & $18(26.86)$ \\
\hline m2/cagA+/iceA2/oipA+/babA2+ & $2(2.98)$ \\
\hline m2/cagA+/iceA2/oipA+/babA2- & $4(5.97)$ \\
\hline m2/cagA+/iceA2/oipA-/babA2+ & $5(7.46)$ \\
\hline m2/cagA+/iceA2/oipA-/babA2- & $6(8.95)$ \\
\hline m2/cagA-/iceA1/oipA+/babA2+ & $3(4.47)$ \\
\hline m2/cagA-/iceA1/oipA+/babA2- & $6(8.95)$ \\
\hline m2/cagA-/iceA1/oipA-/babA2+ & $8(11.94)$ \\
\hline m2/cagA-/iceA1/oipA-/babA2- & $10(14.92)$ \\
\hline m2/cagA-/iceA2/oipA+/babA2+ & $1(1.49)$ \\
\hline m2/cagA-/iceA2/oipA+/babA2- & $3(4.47)$ \\
\hline m2/cagA-/iceA2/oipA-/babA2+ & $3(4.47)$ \\
\hline m2/cagA-/iceA2/oipA-/babA2- & $5(7.46)$ \\
\hline
\end{tabular}

${ }^{a}$ Distribution was achieved based on the total numbers of $67 \mathrm{H}$. pylori isolates

recovered from human clinical samples were also reported previously [53-56].

A possible relationship between virulence factors and antimicrobial resistance has been suggested. A study conducted in 2009 in Ireland reported that the absence of $\operatorname{cagA}$ may be a risk factor for developing metronidazole resistance [57]. Other studies have found an association between clarithromycin resistance mutations and the less virulent $v a c A$ genotypes [58]. Another report revealed that cagE and $v a c A$ S1 correlated with clarithromycin and metronidazole resistance [59], while others found that neither cagA nor $v a c A$ was associated with resistance $[60,61]$. Therefore, it is important to found any significant relationship between the presence of virulence markers and antibiotic resistance amongst the H. pylori strains.

Triple therapy, including two antibiotics, amoxicillin and clarithromycin, and a proton pump inhibitor given for a week has been recommended as the treatment of choice at several consensus conferences [62]. However, this treatment may fail for several reasons, as reported elsewhere [63]. In fact, the main reason for failure was found to be $H$ pylori resistance to one of the antibiotics used (that is, clarithromycin). Other treatments have also been proposed, including metronidazole, a drug for which resistance is also a problem although to a lesser extent, as well as tetracycline, fluoroquinolones, and rifamycins for which resistance has become an emerging issue [64]. Results of the present investigation showed that application of furazolidone, streptomycin and cefsulodin may be effective for treatment of the cases of $H$. pylori infections. Reduction in the antibiotic prescription and also prescription of antibiotics according to the results of the disk diffusion can reduce the risk of antibiotic resistance. Using medicinal plants and especially those with high antimicrobial effects is a practical alternative way for treatment of $H$. pylori infection.

\section{Conclusions}

To put it in a nutshell, we recognized a great numbers of virulent and resistant $H$. pylori bacteria in raw milk samples of bovine, ovine, caprine, buffalo and camel species. Boost incidence of $H$. pylori bacteria in raw milk characterizes that these samples may be the natural reservoirs of the bacteria and can spread $H$. pylori to human. Moreover, some of the H. pylori bacteria of our research harbored vacA, cagA, iceA, oipA and babA2 genotypes together which represents the high pathogenicity. Furthermore, higher prevalence of iceA1+ strains than iceA2+, oipA - than oipA+ and finally babA2- than $b a b A 2+$ is another important finding of our study. Additionally, presence of 97 diverse combined genotyping patterns with high distribution of s1a/cagA+/iceA1/ oipA-/babA2-, m1a/cagA+/iceA1/oipA-/babA2-, s2/ cagA+/iceA1/oipA-/babA2-, $\quad$ sla/cagA+/iceA1/oipA -/babA2+, m1a/cagA+/iceA1/oipA-/babA2+, s2/cagA +/iceA1/oipA-/babA2+, s1a/cagA+/iceA1/oipA+/babA2and $\mathrm{m} 2 / \mathrm{cagA}+$ iceA1/oipA-/babA2+ is another interesting finding of our research. Similarities in the genotyping pattern of $H$. pylori strains between various milk sources represent their same route of infection. High prevalence of multi-drug resistant $H$. pylori strains shows that raw milk of bovine, ovine, caprine, buffalo and camel species may be reservoir of antibiotic resistant $H$. pylori. Prescription of cefsulodin, furazolidone, spiramycin and streptomycin may be effectual for treatment of cases of $H$. pylori infections due to the consumption of raw milk. Additional researches are essential to recognize the rates of the molecular genetic homology of $H$. pylori bacteria isolated from milk and dairy samples and those of human clinical specimens to confirm the zoonotic aspects of $H$. pylori. 


\section{Abbreviations}

BabA: Blood group Antigen-Binding Adhesin gene; CagA: Cytotoxin Associated Gene AlceAlnduced by Contact with the Epithelium Antigen; $H$. pylori: Helicobacter pylori; Oip: Outer Inflammatory Protein; PCR: Polymerase Chain Reaction; SPSS: Statistical Package for the Social Sciences; VacA: Vacuolating Cytotoxin A

\section{Acknowledgements}

The authors would like to thank Prof. Ebrahim Rahimi and Dr. Manouchehr Momeni Shahraki for their assistance in laboratory-based examinations. Authors would also thank from Dr. Mojtaba Masoudimanesh, Dr. Amirthossein Sheikhshahrokh and Dr. Mohammad Hossein Sakhaei Shahreza for their important assistance in the samples collection and statistical analysis. We would also like to thank from the "Clinical Research Development Center of Baqiyatallah hospital" for their kindly cooperation. This study was supported in part by a grant from "Clinical Research Development Center of Baqiyatallah hospital".

\section{Funding}

This work was supported by a grant provided from "Clinical Research Development Center of Baqiyatallah hospital" and the Molecular Biology Research Center, Systems Biology and Poisonings Institute, Baqiyatallah University of Medical Sciences, Tehran, Iran (grant no. 97/23).

\section{Availability of data and materials}

All data generated or analyzed throughout this research are included in this published article.

\section{Authors' contributions}

FSD designed the study and carried out the PCR genetic alignment. RR supported the study and carried out the culture-based identification, disk diffusion and statistical analysis. FYF carried out the sample collection and preparation and writing of the manuscript. RR carried out the drafting of the manuscript. All authors read and approved the final manuscript.

\section{Ethics approval and consent to participate}

The study was approved by the Ethical Council of Research of the Molecular Biology Research Center, Baqiyatallah University of Medical Sciences, Tehran, Iran (Consent Ref Number 97-23). Verification of this research project and the licenses related to sampling process were approved by the Prof. Reza Ranjbar (Approval Ref Number FHQC 2017/23).

\section{Consent for publication}

There was no consent for publication.

\section{Competing interests}

The authors declare that they have no competing interests.

\section{Publisher's Note}

Springer Nature remains neutral with regard to jurisdictional claims in published maps and institutional affiliations.

\section{Author details}

${ }^{1}$ Molecular Biology Research Center, Systems Biology and Poisonings Institute, Baqiyatallah University of Medical Sciences, Tehran, Iran. ${ }^{2}$ Molecular Biology Research Center, Systems Biology and Poisonings Institute, Baqiyatallah University of Medical Sciences, Tehran, Iran. ${ }^{3}$ Young Researchers and Elites Club, Shahrekord Branch, Islamic Azad University, Shahrekord, Iran.

Received: 31 July 2018 Accepted: 17 September 2018

Published online: 29 September 2018

\section{References}

1. Thorning TK, Raben A, Tholstrup T, Soedamah-Muthu SS, Givens I, Astrup A. Milk and dairy products: good or bad for human health? An assessment of the totality of scientific evidence. Food Nutr Res. 2016;60:32527.

2. Safarpoor Dehkordi F, Valizadeh Y, Birgani T, Dehkordi K. Prevalence study of Brucella melitensis and Brucella abortus in cow's milk using dot enzyme linked immuno sorbent assay and duplex polymerase chain reaction. J Pure Appl Microbiol. 2014;8:1065-9.
3. Momtaz H, Safarpoor Dehkordi F, Taktaz T, Rezvani A, Yarali S. Shiga toxinproducing Escherichia coli isolated from bovine mastitic milk: serogroups, virulence factors, and antibiotic resistance properties. Sci World J. 2012;2012: $1-9$.

4. Rahimi E, Sepehri S, Dehkordi FS, Shaygan S, Momtaz H. Prevalence of Yersinia species in traditional and commercial dairy products in Isfahan Province, Iran. Jundishapur J Microbiol. 2014;7.

5. Ranjbar R, Dehkordi FS, Shahreza MHS, Rahimi E. Prevalence, identification of virulence factors, O-serogroups and antibiotic resistance properties of Shiga-toxin producing Escherichia coli strains isolated from raw milk and traditional dairy products. Antimicrob Resist Infect Control. 2018;7:53.

6. Safarpoor Dehkordi F, Barati S, Momtaz H, Hosseini Ahari SN, Nejat Dehkordi S. Comparison of shedding, and antibiotic resistance properties of listeria monocytogenes isolated from milk, feces, urine, and vaginal secretion of bovine, ovine, caprine, buffalo, and camel species in Iran. Jundishapur J Microbiol. 2013:6:284-94.

7. Atapoor S, Dehkordi FS, Rahimi E. Detection of helicobacter pylori in various types of vegetables and salads. Jundishapur J Microbiol. 2014;7:e10013.

8. Ghorbani F, Gheisari E, Dehkordi FS. Genotyping of vacA alleles of helicobacter pylori strains recovered from some Iranian food items. Trop J Pharm Res. 2016;15:1631-6.

9. Yahaghi E, Khamesipour F, Mashayekhi F, Safarpoor Dehkordi F, Sakhaei MH, Masoudimanesh $\mathrm{M}$, et al. Helicobacter pylori in vegetables and salads: genotyping and antimicrobial resistance properties. Biomed Res Int. 2014;2014:1-11.

10. Mousavi S, Dehkordi FS, Rahimi E. Virulence factors and antibiotic resistance of helicobacter pylori isolated from raw milk and unpasteurized dairy products in Iran. J Venom Anim Toxins Incl Trop Dis. 2014;20:51.

11. Biernat MM, Gościniak G, Iwańczak B. Prevalence of helicobacter pylori cagA, vacA, iceA, babA2 genotypes in polish children and adolescents with gastroduodenal disease. Adv Hyg Experiment Med. 2014;68:1015-21.

12. Alba C, Blanco A, Alarcón T. Antibiotic resistance in helicobacter pylori. Curr Opin Infect Dis. 2017:30:489-97.

13. Ranjbar R, Khamesipour F, Jonaidi-Jafari N, Rahimi E. Helicobacter pylori in bottled mineral water: genotyping and antimicrobial resistance properties. BMC Microbiol. 2016;16:40.

14. Ranjbar R, Khamesipour F, Jonaidi-Jafari N, Rahimi E. Helicobacter pylori isolated from Iranian drinking water: vacA, cagA, iceA, oipA and babA2 genotype status and antimicrobial resistance properties. FEBS Open Bio. 2016;6:433-41.

15. Ho S-A, Hoyle J, Lewis F, Secker A, Cross D, Mapstone N, et al. Direct polymerase chain reaction test for detection of helicobacter pylori in humans and animals. J Clin Microbiol. 1991;29:2543-9.

16. Andrews J. BSAC disc diffusion method for antimicrobial susceptibility testing. 2.1.4 ed. British Society for Antimicrobial Chemotherapy: Birmingham, UK; 2003.

17. NCCLS. Performance Standards for Antimicrobial Susceptibility Testing. Approved Standard M7-A5: Informational Supplement M100- S18. National Committee for Clinical Laboratory Standards: Wayne, PA; 2007.

18. Glupczynski Y, Megraud F, Lopez-Brea M, Andersen L. European multicentre survey of in vitro antimicrobial resistance in helicobacter pylori. Eur J Clin Microbiol Infect Dis. 2001:20:820-3.

19. Yamazaki S, Yamakawa A, Okuda T, Ohtani M, Suto H, Ito Y, et al. Distinct diversity of vacA, cagA, and cagE genes of helicobacter pylori associated with peptic ulcer in Japan. J Clin Microbiol. 2005;43:3906-16.

20. Wang J, Chi DS, Laffan JJ, Li C, Ferguson DA, Litchfield P, et al. Comparison of cytotoxin genotypes of helicobacter pylori in stomach and saliva. Digest Dis Sci. 2002;47:1850-6.

21. Peek JR, Thompson SA, Donahue JP, Tham KT, Atherton JC, Blaser MJ, et al. Adherence to gastric epithelial cells induces expression of a helicobacter pylori gene, iceA, that is associated with clinical outcome. Proc Assoc Am Physicians. 1998;110:531-44.

22. Sheu B, Sheu $S$, Yang $H$, Huang A, Wu J-J. Host gastric Lewis expression determines the bacterial density of helicobacter pylori in babA2 genopositive infection. Gut. 2003;52:927-32.

23. Dore MP, Sepulveda AR, El-Zimaity H, Yamaoka Y, Osato MS, Mototsugu K et al. Isolation of helicobacter pylori from sheep-implications for transmission to humans. Am J Gastroenterol. 2001;96:1396.

24. Bui D, Brown HE, Harris RB, Oren E. Serologic evidence for fecal-oral transmission of helicobacter pylori. Am J Trop Med Hyg. 2016;94:82-8. 
25. Mard SA, Khadem Haghighian H, Sebghatulahi V, Ahmadi B. Dietary factors in relation to helicobacter pylori infection. Gastroenterol Res Pract. 2014;2014:1-5.

26. Stevenson TH, Bauer N, Lucia LM, Acuff GR. Attempts to isolate helicobacter from cattle and survival of helicobacter pylori in beef products. J Food Prot. 2000;63:174-8

27. Poms RE, Tatini SR. Survival of helicobacter pylori in ready-to-eat foods at 4 C. Int J Food Microbiol. 2001;63:281-6.

28. Meng X, Zhang H, Law J, Tsang R, Tsang T. Detection of helicobacter pylori from food sources by a novel multiplex PCR assay. J Food Safety. 2008;28:609-19.

29. Jiang X, Doyle MP. Optimizing enrichment culture conditions for detecting helicobacter pylori in foods. J Food Prot. 2002;65:1949-54.

30. Herrera AG. Helicobacter pylori and food products. Public Health Microbiol. 2004:297-301.

31. Quaglia N, Dambrosio A, Normanno G, Parisi A, Firinu A, Lorusso V, et al. Survival of helicobacter pylori in artificially contaminated ultrahigh temperature and pasteurized milk. Food Microbiol. 2007;24:296-300.

32. Fujimura $\mathrm{S}$, Kawamura $\mathrm{T}$, Kato $\mathrm{S}$, Tateno $\mathrm{H}$, Watanabe A. Detection of helicobacter pylori in cow's milk. Lett Appl Microbiol. 2002;35:504-7.

33. Vale F, Vítor J. Transmission pathway of helicobacter pylori: does food play a role in rural and urban areas? Int J Food Microbiol. 2010;138:1-12.

34. Angelidis AS, Tirodimos I, Bobos M, Kalamaki MS, Papageorgiou DK, Arvanitidou M. Detection of helicobacter pylori in raw bovine milk by fluorescence in situ hybridization (FISH). Int J Food Microbiol. 2011;151:252-6

35. Quaglia N, Dambrosio A, Normanno G, Parisi A, Patrono R, Ranieri G, et al. High occurrence of helicobacter pylori in raw goat, sheep and cow milk inferred by glmM gene: a risk of food-borne infection? Int J Food Microbiol. 2008; $124: 43-7$

36. Talaei R, Souod N, Momtaz H, Dabiri H. Milk of livestock as a possible transmission route of helicobacter pylori infection. Gastroenterol Hepatol Bed Bench. 2015;8:S30

37. Rahimi E, Kheirabadi EK. Detection of helicobacter pylori in bovine, buffalo, camel, ovine, and caprine milk in Iran. Foodborne Pathog Dis. 2012;9:453-6.

38. Osman EY, El-Eragi A, Musa AM, El-Magboul SB. Detection of helicobacter pylori glmM gene in bovine milk using nested polymerase chain reaction. Vet World. 2015:8:913.

39. Bianchini V, Recordati C, Borella L, Gualdi V, Scanziani E, Selvatico E, et al. Helicobacteraceae in bulk tank milk of dairy herds from northern Italy. Biomed Res Int. 2015;2015:1-4.

40. Safaei HG, Rahimi E, Zandi A, Rashidipour A. Helicobacter pylori as a zoonotic infection: the detection of $\mathrm{H}$ pylori antigens in the milk and faeces of cows. J Res Med Sci. 2011;16:184

41. Zamani M, Vahedi A, Maghdouri Z, Shokri-Shirvani J. Role of food in environmental transmission of helicobacter pylori. Caspian J Int Med. 2017:8:146.

42. Talimkhani A, Mashak Z. Prevalence and genotyping of helicobacter pylori isolated from meat, Milk and vegetable in Iran. Jundishapur J Microbiol. 2017;10.

43. Khaji L, Banisharif G, Alavi I. Genotyping of the helicobacter pylori isolates of raw milk and traditional dairy products. Microbiol Res. 2017;8:43-6.

44. Esmaeiligoudarzi D, Tameshkel FS, Ajdarkosh H, Arsalani M, Sohani MH, Behnod V. Prevalence of helicobacter pyloriinlranian milk and dairy products using culture and ureC based-PCR techniques. Biomed Pharmacol J. 2015:8:179-83

45. Saeidi E, Sheikhshahrokh A. VacA genotype status of helicobacter pylori isolated from foods with animal origin. Biomed Res Int. 2016;2016:1-6.

46. Hemmatinezhad B, Momtaz H, Rahimi E. VacA, cagA, iceA and oipA genotypes status and antimicrobial resistance properties of helicobacter pylori isolated from various types of ready to eat foods. Ann Clin Microbiol Antimicrob. 2016;15:2.

47. Hunt R, Xiao S, Megraud F, Leon-Barua R, Bazzoli F, Van der Merwe S, et al. Helicobacter pylori in developing countries. J Gastrointestin Liver Dis. 2011;20:299-304.

48. Torkan S, Shahreza MHS. VacA, CagA, IceA and OipA genotype status of helicobacter pylori isolated from biopsy samples from Iranian dogs. Trop J Pharmaceu Res. 2016;15:377-84.

49. Dabiri H, Jafari F, Baghaei K, Shokrzadeh L, Abdi S, Pourhoseingholi MA, et al. Prevalence of helicobacter pylori vacA, cagA, cagE, oipA, iceA, babA2 and babB genotypes in Iranian dyspeptic patients. Microb Pathog. 2017;105:226-30.
50. Podzorski RP, Podzorski DS, Wuerth A, Tolia V. Analysis of the vacA, cagA, cagE, iceA, and babA2 genes in helicobacter pylori from sixty-one pediatric patients from the Midwestern United States. Diagn Microbiol Infect Dis. 2003:46:83-8.

51. Momtaz H, Dabiri H, Souod N, Gholami M. Study of helicobacter pylori genotype status in cows, sheep, goats and human beings. BMC Gastroenterol. 2014;14:61.

52. Gilani A, Razavilar V, Rokni N, Rahimi E. VacA and cagA genotypes status and antimicrobial resistance properties of helicobacter pylori strains isolated from meat products in Isfahan province. Iran Iran J Vet Res. 2017;18:97.

53. Pakbaz Z, Shirazi MH, Ranjbar R. Frequency of sabA gene in helicobacter pylori strains isolated from patients in Tehran, Iran. Iran Red Crescent Med J. 2013;15:767.

54. Souod N, Kargar M, Doosti A, Ranjbar R, Sarshar M. Genetic analysis of cagA and vacA genes in helicobacter pylori isolates and their relationship with gastroduodenal diseases in the west of Iran. Iran Red Crescent Med J. 2013;15:371.

55. Farshad S, Alborzi A, Japoni A, Ranjbar R, Asl KH, Badiee P, et al. Antimicrobial susceptibility of helicobacter pylori strains isolated from patients in shiraz, southern Iran. World J Gastroenterol. 2010;16:5746.

56. Ghasemi A, Shirazi M, Ranjbar R, Khorramizadeh M, Daryani N, Hosseini M. The prevalence of cagA and cagE genes in helicobacter pylori strains isolated from different patient groups by polymerase chain reaction. Pak J Biol Sci. 2008;11:2579-83.

57. Taneike I, Nami A, O'Connor A, Fitzgerald N, Murphy P, Qasim A, et al. Analysis of drug resistance and virulence-factor genotype of Irish helicobacter pylori strains: is there any relationship between resistance to metronidazole and cagA status? Aliment Pharmacol Ther. 2009;30:784-90.

58. Boyanova L, Markovska R, Yordanov D, Gergova G, Mitov I. Clarithromycin resistance mutations in helicobacter pylori in association with virulence factors and antibiotic susceptibility of the strains. Microb Drug Resist. 2016;22:227-32.

59. Karabiber H, Selimoglu MA, Otlu B, Yildirim O, Ozer A. Virulence factors and antibiotic resistance in children with helicobacter pylori gastritis. J Pediatr Gastroenterol Nutr. 2014;58:608-12.

60. van Doorn LJ, Glupczynski Y, Kusters JG, Mégraud F, Midolo P, Maggi-Solcà $\mathrm{N}$, et al. Accurate prediction of macrolide resistance in helicobacter pylori by a PCR line probe assay for detection of mutations in the $23 \mathrm{~S}$ rRNA gene: multicenter validation study. Antimicrob Agents Chemother. 2001;45:1500-4.

61. Godoy AP, Ribeiro ML, Benvengo YH, Vitiello L, Miranda Mde C, Mendonça $S$, et al. Analysis of antimicrobial susceptibility and virulence factors in helicobacter pylori clinical isolates. BMC Gastroenterol. 2003;3:20.

62. European Helicobacter pylori Study Group. Current European concepts in the management of helicobacter pylori infection. The Maastricht consensus report. Gut. 1997;41:8-13.

63. Mégraud $F$, Lamouliatte $H$. The treatment of refractory helicobacter pylori infection. Aliment Pharmacol Ther. 2003;17:1333-43.

64. Mégraud F, Hazell S, Glupczynski Y. Antibiotic susceptibility and resistance. In: Mobley HLT, Mendz GL, Hazell SL, editors. Helicobacter pylori: physiology and genetics. Washington, DC: ASM Press; 2001. p. 511-30.

\section{Ready to submit your research? Choose BMC and benefit from:}

- fast, convenient online submission

- thorough peer review by experienced researchers in your field

- rapid publication on acceptance

- support for research data, including large and complex data types

- gold Open Access which fosters wider collaboration and increased citations

- maximum visibility for your research: over $100 \mathrm{M}$ website views per year

At $\mathrm{BMC}$, research is always in progress.

Learn more biomedcentral.com/submissions 